\title{
Implementation of Information System on the Planting Time Prediction Based on Climate Modelling
}

\author{
Armi Susandi”, Mamad Tamamadin *, Irsal Las *, Erizal Jamal ${ }^{4}$ \\ \# Department of Meteorology, Institut Teknologi Bandung, \\ Labtek XI Building floor 1, Jalan Ganesa 10 Bandung 40132, Indonesia \\ E-mail:armi@meteo.itb.ac.id \\ * Department of Meteorology, Institut Teknologi Bandung, \\ Labtek XI Building floor 1, Jalan Ganesa 10 Bandung 40132, Indonesia \\ E-mail:mamadtama@meteo.itb.ac.id \\ "Indonesian Agroclimate and Hydrology Research Institute, Ministry of Agriculture, \\ Jl. Tentara Pelajar No. 1A Bogor 16111, Indonesia \\ E-mail:irsallas@yahoo.com \\ ${ }^{4}$ Indonesian Institute for Agricultural Technology Transfer (IIATT), Ministry of Agriculture \\ Jl. Salak 22 Bogor, Indonesia \\ E-mail: erizal_jamal@yahoo.com
}

\begin{abstract}
Changes in rainfall patterns due to climate change have resulted in losses of farmers in Indramayu. Farmers has loss of economic due to failing of planting and harvesting every year in this location. Therefore, farmers need information on future rainfall prediction to plant rice accurately and on time. The information system should be able to be easily accessed by farmers and extension. This paper discuss research result on rainfall prediction system and planting rice with high resolution in dasarian (10-days) scale. The information system includes predictive technology using Geographic Information System (GIS) with input from Smart Climate Modelling using stochastic approach. Information delivery system was developed in line with the predictions of rainfall information and feedback planting season comes to evaluate the predicted results. Such information will be dynamically run through overlaying with Google maps on the web server. This system can be accessed by the public and was designed to automatically generate maps of rainfall and planting prediction that can be viewed directly in the Google maps application. This research result will be effort to adapt to climate change that has impacted to agriculture sector in Indonesia.
\end{abstract}

Keywords - climate modelling; Google maps; information delivery system; planting time prediction; rainfall prediction.

\section{INTRODUCTION}

This Rice as a main food source in Indonesia is currently occurring decline of the production as a result of changes of rainfall patterns. This happened in the last few years in West Java, as released by Central Agency of Statistic in West Java in 2012 due to decrease of rice harvest and productivity. The decline of rice production between 2012 and 2011 reaching 3.11 percent, recorded that yield is 7.299 million tons in $2011[1]$.

One of the main benchmark parameters of the rice productivity and quality is rainfall. These parameters must be estimated precisely in time so that the farmers can sustain rice productivity. The results of the previous study showed that the climate models achieved a very high accuracy and has been built become maps of the rice planting prediction in high resolution up to village level. Through the prediction of more accurate rice planting, it is expected that farmers will be able to reduce the failure of planting season.

To continue the previous research [2], information system has been built containing the rice planting predictions and recommendations using websites. Farmers, agricultural extension, and agricultural services in Indramayu will benefit directly as using this ICT application. Therefore hopefully, farmers will be able to reduce the risk of failed crops and harvest, and will support national economic 
development in the agricultural industry. This technology is one of the innovations in agriculture field that will support the National Innovation System, especially in the agricultural sector, in particular for food technology.

\section{METHODS}

Agricultural information system has been established in the meteorological information system by developing an online database system. The pattern of information system is in general reflecting the real-world such that the data are abstracted into a group basis. These data were processed using the functions, and then delivered to the user in form of the desired information (Figure 1).

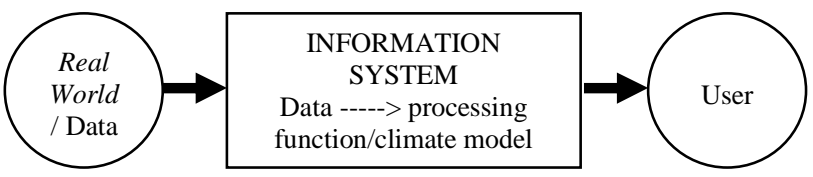

Fig. 1. Flow of information system

Programming concept has been constructed with the following stages: (1) build a database that consists of tables of rainfall prediction and wetlands, (2) prepare wetland maps library that is connected to the wetland table in the database, (3) establish administrative maps in villages scale overlaid with Google maps, and (4) build the entire wetland map overlaid with Google maps as seen in the Figure 2.

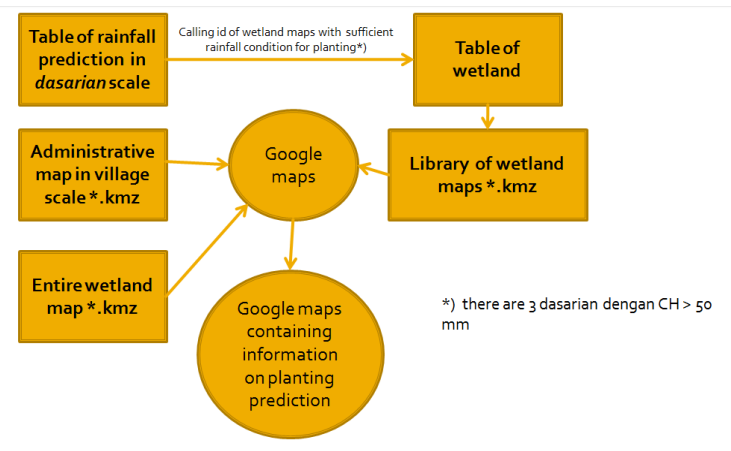

Fig. 2. flow chart of rice planting information system

Prediction information will not be displayed in one step, but through several stages. Information will be going through the stages of validation that can improve the accuracy of prediction by comparing the predicted results with the observational data in the field. The data and information will be obtained from the farmers and stakeholders in the case area.

To build information systems in agriculture which contains information on the future plans of website based rice planting in Indramayu, then take a few things, namely the domain name, hosting, database, and website interface design. Website development was done using PHP programming language and using MySQL database. Climate prediction data that has been generated by the climate model directly in entry to the database. Interface in the browser will display the time of prediction and climate parameters desired. Furthermore, the browser will be able to directly display in the form of a spatial map in accordance with the desired prediction time.

\section{RESULT AND DISCUSSION}

Here is the result of the website development on the information system on rainfall prediction and rice planting time estimation in dasarian scale implemented in the District of Indramayu, West Java.

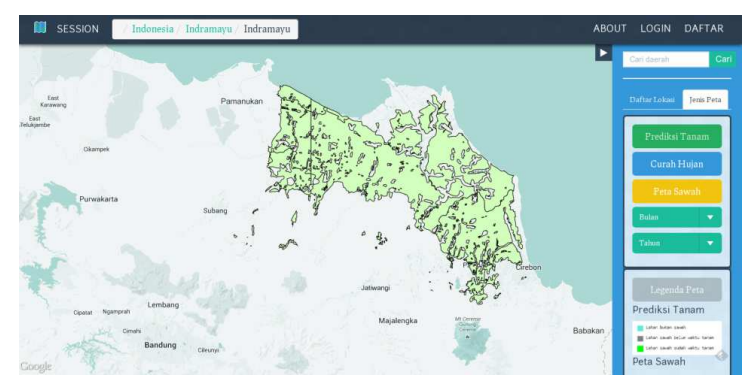

Fig. 3.Information system on wetland

Figure 3 shows the interface of information system on the wetland in Indramayu district. This wetland maps will be overlaid automatically with Google maps by the website server to generate any areas that are ready to planting rice. The wetland map will be base for the rice planting estimation after processing the 3 dasarian of rainfall prediction in a village wetland. This procedure follow the result of research mentioning [3]:

- Treshold of rice production in non-irrigation area can be obtained as rainfall of $600 \mathrm{~mm}$ or $50 \mathrm{~mm} / \mathrm{ten}$ days.

- $\quad$ Rice planting can be started in after the backward and forward ten days rainfall reaching $50 \mathrm{~mm}$.

Before showing the rice planting estimation, website will also display the rainfall prediction in dasarian scale in Indramayu. This prediction was obtained from the processing of smart climate model that has been built by the research team [4]. The display of rainfall prediction will be initialized by the prediction in the date. After that, users could customize the date and in what scale users would like to display. In the case of rainfall information, website could also display the specific information on magnitude of rainfall and scale of the rainfall, including high, moderate, and dry scale (see Figure 4). For separating information on the rainfall prediction each village, the maps was overlaid with the administrative maps in village scale displayed with the black outline.

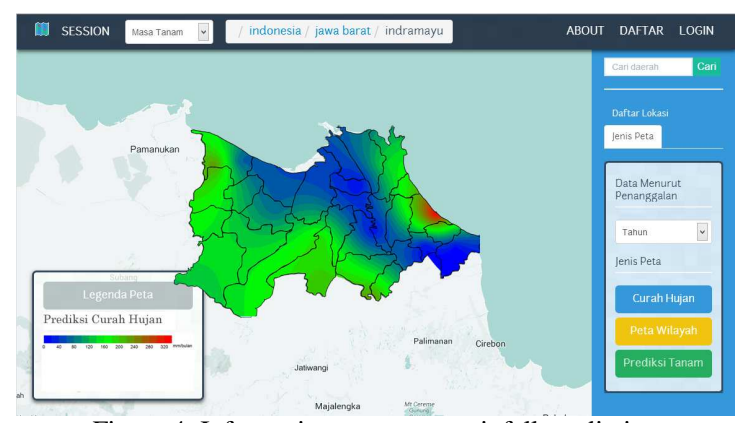

Figure 4. Information system on rainfall prediction 
The most useful information needed by farmers is rice planting estimation. Through this information, farmers could plan the rice planting in next session. Farmers could prepare the seeding, wetland processing, human resources for managing the wetland, and others. Figure 5 show the display of rice planting estimation in dasarian scale marked by green shading for wetland that could be already planted by rice seed. This information will be easy to access by extension and delivered to farmers in Indramayu.

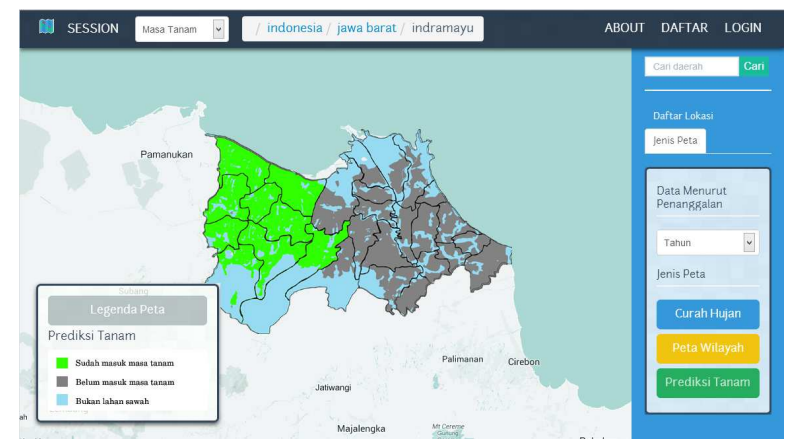

Figure 5. Information system on rice planting estimation

Other shading of map is gray describing the wetland that could not be planted by the rice seed since the rainfall on that area has not been yet sufficient for the planting of rice. And green blue shading show the map of Indramayu district that is not the wetland. As information of rainfall prediction, this information on rice planting estimation also display the specific information on recommendation for preparing the planting. Based the rainfall prediction, website will recommend the time for seeding and wetland processing.

The accurate of preparation time in the planting activities hopefully maintain the percentage of rice production. This condition of previously has been simulated using crop modeling where farmers follow the rainfall prediction and subsequently utilize the rainfall during the planting season as predicted, therefore farmers will get the optimal yield of rice. The optimal yield will be obtained if farmers follow all recommendation as resulted by the model.

Urgently, farmers most need the information on rice planting time. Research team has survey to farmers in several area of main food production in Indonesia and conclude that almost farmers want reference the information for their planting activities in the future season. However in the scientific area, this information system is also a necessary input in the research process in the sense that a researcher must have access to previously recorded knowledge about the researcher's area of investigation [5]. Researcher will gain the advance study to develop the model and information system to help farmers in maintaining their rice production and also support the national food security.

Effective strategies and policies to promote the sustainable development of agriculture and the rural milieu require an information system to monitor and evaluate their implementation and impact and provide, in a timely fashion, continuous input for policymakers (analysts and authorities in the executive and legislative branches as well as the judiciary and leaders of other groups of stakeholders) on the evolution of agriculture [6].

\section{CONCLUSIONS}

This study to date has resulted in the prediction maps of rice planting in dasarian scale, database design, and a feedback page. There are several conclusions that can be drawn, as follows:

1. Map of the rice planting time estimation should be built automatically in online server in order to make easy on evaluating the prediction result.

2. While for map of rainfall prediction should be built offline, because Google maps does not provide a feature interpolation of Krigging to build a contour map of rainfall.

3. Database and interface design is now done, next is to develop a dynamic interface with input from climate model results and interactive response.

\section{ACKNOWLEDGMENT}

We would like to thank to Dr.Ir. Haris Syahbuddin, DEA as Head of Indonesian Agroclimate and Hydrology Research Institute, Ministry of Agriculture for being partner during the research. Secondly, we would also like to thank Ministry of Research and Technology and Directorate General of Higher Education (Dirjen DIKTI) for supporting this research. Furthermore, we would also thank to Bappeda (Regional Planning Agency of Indramayu District) for helping in coordination between research team and farmers and agricultural extension in Indramayu.

\section{REFERENCES}

[1] Central Agency on Statistic (BPS) of West Java Province. Official News on Statistic. No. 15/03/32/Th. XVI, 3 March 2014

[2] Susandi, A., Djamal, E., Las, I., Tamamadin, M., Surmaini, E., Development of High Resolution Planting Calendar Map to Increase of Rice Productivity in Indramayu. Proceedings of The 2nd International Conference On Green World in Business and Technology, Published by UAS Press, March 2013 (p. E-1)

[3] Susandi, A., Djamal, E., Las, I., Tamamadin, M., Surmaini, E., Stochastic Climate Model for Implementation in Rice Planting Planning. Proceedings of the HAGI-IAGI Joint Convention Medan 2013

[4] Tamamadin, M., Susandi, A., Evaluation of Climate Modeling using Fast Fourier Transform Methods for Determining Rice Planting Time, Proceeding of National Scientific Conference of the $8^{\text {th }}$

Environmental Problem Researches in Indonesia, University of Gadjah Mada, Yogyakarta, 12 July 2012

[5] Kaaya, Janet, Role of Informaiton Technology in Agriculture. Proceedings of FoA conference Vol. 4, 1999

[6] Casas, LDL., Gatica, J., Jimenez, F., Information System for Monitoring and Evaluating Strategies and Policies for Agriculture and Rural Life. The Ministerial Process and Ministerial Meetings Agriculture and Rural Life in the Americas”. 2007 